\title{
Beiträge zur Kenntniss der Wirbelthiere Südbrasiliens.
}

Von

Dr. Reinhold Hensel.

(Fortsetzung.)

In der vorhergehenden Abtheilung dieser Beiträge habe ich schon 12 Species der Fische beschrieben ${ }^{1}$ ). In diesem Beitrage folgt die Beschreibung aller übrigen von mir in der Provinz Rio Grande do Sul gesammelten Fische, doch habe ich der Vollständigkeit wegen nochmals die Namen der schon in der früheren Abtheilung beschriebenen Arten aufgeführt, obgleich ohne Nummer. In der Systematischen Anordnung bin ich Günthers Catal. Fish. gefolgt.

13. Sciaena adusta Agass. (Spix, Pise. Bras. p. 126, tab. 70).

D. $10 / 1 \times 30$. A. $2 / 9$. P. $1 / 17$. L. lat. 52 . Vent. $7 / 15$.

Die Höhe des Körpers ist $3^{1 / 2} \mathrm{mal}$ in der Länge desselben (ohne Schwanzflosse) enthalten und beträgt $5 / 6$ der Länge des Kopfes. Der Unterkiefer wird nur wenig. vom Oberkiefer überragt. Der 2te Stachel in der Analflosse halb so lang wie die zunächst folgenden weichen Strahlen. Das Praeoperculum auf der Hinterseite gezähnelt, die unteren Zähne grösser, dornartig, am Winkel desselben zwei grössere um den Durchmesser der Pupille von einander entfernte Dornen, der obere mehr nach

1) Vergl. Dieses Archiv Jahrg. 34. Bd. 1. p. 356-375. 
hinten, der untere mehr nach unten gerichtet. Die vorderen Zähne in beiden Kiefern nur wenig grösser als die hintern, die Grösse der Zähne nimmt von vorn nach hinten nur allmählich ab. Die Farbe der Bauchseite silberweiss, der Rückenseite hat zwar eine silbergraue Grundfarbe, allein schmale (in Spirit.) bräunliche Bänder laufen schräg nach oben und hinten, indem je ein solches Band die Mitte einer der schräg nach hinten aufsteigenden Schuppenreihen einnimmt. Die Rückenflosse ist unbeschuppt, die Schwanzflosse beschuppt, beide sind ganz schwach grau pigmentirt, die übrigen Flossen sind (in Spirit.) weiss.

Dieser Fisch findet sich vorzugsweise bei Rio Grande, doch kommt er auch in den Guahyla bei Porto Alegre vor und führt hier den Namen Cruvina.

Die Farbe an den beiden mir vorliegenden Exemplaren stimmt wenig mit der oben citirten Abbildung in Spix, Pisc. Bras. und auch von $\mathrm{G}$ ü $\mathrm{n}$ ther (Catal. Fish. II, p. 289) werden alle Flossen "schwärzlich" genannt, doch scheinen die von Jenyns l. c. p. 42 , beschriebenen Exemplare von Maldonado und Montevideo den meinen zu gleichen.

\section{Mugil liza Cuv. Val. Hist. nat. Poiss. XI. p. 83.}

Dieser von Brasilianern Dainha (spr. Daïnje) genannte Fisch gehört eigentlich dem Meere an, geht aber auch weit in die Flüsse hinauf. So beobachtete ich ihn in den ersten Monaten des Jahres 1864, also im Sommer, in grosser Menge bei Porto Alegre, wenigstens 36 Meilen vom Meere entfernt. Doch hielten sich hier die Fische ihrer Natur getreu stets im offenen und tiefen Wasser auf, während die wirklichen Süsswasserfische die Buchten und alle ruhigen mit Wasserpflanzen besetzten Stellen bevorzugen. Die Dainha zeichnet sich durch eine ausserordentliche Springfähigkeit aus, und beständig sieht man Fische mehr oder weniger senkrecht aus dem Wasser herausspringen, oft bis zur Höhe eines Mannes. Durch Feind, konnten die Thiere nicht dazu veranlasst werden, aucl laichen sie vielleicht nicht im süssen Wasser, denn ir: 
dem salzwasserhaltigen Hafen von Montevideo fing ich ein sehr kleines Exemplar des Mugil.

Mit dieser Schnellkraft des Fisches hängt auch der Bau des Rückens zusammen, der durch die starke Entwicklung seiner Muskeln, durch seine breite und kantige Gestalt sehr an Exocoetus erinnert.

Merkwürdigerweise wollen sich ältere Leute in Porto Alegre nicht erinnern, die Dainha früher daselbst gesehen zu haben. Sie soll sich erst seit einigen Jahren periodisch daselbst einfinden. In den Sommer- (Winter-) monaten des Jahres 1866, ungefähr Mai, Juni, Juli habe ich nicht ein einziges Exemplar der Dainha zu Porto Alegre beobachtet.

15. Acara portalegrensis n. sp.

D. ${ }^{14}-15 / 10^{-11}$. A. $3 / 9$. L. lat. 22 .

Drei Schuppenreihen auf den Backen. Die Breite des Praeorbitale etwas schmäler als der Durchmesser des Auges. Hellgrün mit dunkelgrünen Querstreifen. Ein undeutlicher Fleck unter dem Auge, am oberen Ende des Operculum unterhalb der Seitenlinie, fast in der Mitte der Seite ungefähr im zweiten Querstreifen unterhalb der Seitenlinie und in der achten und neunten Schuppenreihe. $\mathrm{Zwischen}$ diešen beiden Flecken ist ein sehr undeutliches dunkles Längsband zu bemerken, dass aber auch von den hellen Zwischenräumen zwischen den Querstreifen unterbrochen sein kann. An der Schwanzwurzel, oberhalb der Seitenlinie ein kleiner dunkler Fleck. Die Flossen grau. Die Rückenflosse und die Analflosse nur in ihrem hintersten Theile dunkel und hell gestreift. An der Schwanzflosse wechseln auf der Flossenhaut schmale graue Streifen mit hellen $a b$; und zwar sind sie, soweit die 6 oberen Strahlen reichen, von hinten nach oben und vorn gerichtet, auch sind hier die hellen Streifen breiter als die dunkeln, an den übrigen Strahlen gehen sie schräg von hinten nach unten und vorn. Hier sind auch die hellen und dunklen Streifen gleich breit.

Diese Art gleicht nach der von $\mathrm{He} \mathrm{ck} \mathrm{el} \mathrm{l.c.} \mathrm{p.} 343$ gegebenen Beschreibung der A. viridis sehr, unterscheidet 
sich aber von ihr durch die gefleckten Flossen und die geringe Zahl der Querschuppenreihen. Die Breite der Stirn zwischen den Augen ist fast doppelt so gross wie der Durchmesser dieser. Die grösste Dicke des Thieres gleich der halben Höhe. Die Höhe gleich der Hälfte der Länge (ohne Schwanzflosse). Die Brustflossen reichen bis auf die 11te Schuppenreihe. An den Bauchflossen reicht der erste fadenförmig verlängerte weiche Strahl fast bis zur Spitze des zurückgelegten dritten Analstachels. Die Analflosse reicht angedrückt mit ihrer Spitze fast soweit nach hinten wie die Rückenflosse und ungefähr bis in die Hälfte der Schwanzflosse. Diese ist abgerundet. Unter 11 Exemplaren besitzt das grösste derselben eine Totallänge von $140 \mathrm{Mm}$. wovon ungefähr 39 auf die Schwanzflosse kommen. Bei Porto Alegre in stagnirenden Gewässern.

16. Acara minuta n. sp.

D. ${ }^{14} / 12$. A. $3 / 8$. C. 17 . P. 14 . V. $1 / 5$, L. lat. 28 .

Die vorderen Fortsätze des äusseren Kiemenbogens kurz, warzenförmig. Die Backen sowie der ganze Kiemendeckel ohne Schuppen. Der Schwanz ziemlich lang. Die Entfernung vom hinteren Ende der Basis der Rükkenflosse bis zum Anfang der Schwanzflosse nur wenig länger als die Höhe des Schwanzes, so lang wie die Entfernung der Schnauzenspitze vom Auge. 8-9 dunkle Querstreifen auf den Seiten, in deren Mitte ein dunkler Fleck.

Die Höhe des Körpers beträgt $2 / 5$ der Länge desselben (ohne Schwanzflosse). Die Länge des Kopfes kaum kleiner als die Höhe des Körpers. Der Raum zwischen den Augen wenig kleiner als der Durchmesser derselben. Die Kiefer gleich lang. Der Mund klein. Die Zähne fein und spitz, die grösseren etwas braun gefärbt. Die Schuppen ctenoïd, ziemlich gross. Die Seitenlinie unterbrochen, ihr vorderer Theil durch 2 vollständige Schuppenreihen von der Rückenflosse getrennt, geht über 17 Querreihen der Schuppen, d. h. bis unter den 4ten weichen Strahl der Rückenflosse. Der hintere 
Theil der Seitenlinie geht über 11 Schuppenreihen und verläuft genau in der Mittellinie der Seite. Unterhalb der vorderen Seitenlinie befinden sich 10 Längsreihen der Schuppen. Nur die Schwanzflosse an ihrer Basis etwas beschuppt. Die Farbe im Leben grünlich, (im Spiritus bräunlich), auf hellem Grunde mit 8-9 dunkleren Querstreifen, die im Vordertheile nicht deutlich getrennt sind, denn man kann hier auf dem Rücken mehr oder weniger deutlich 3 Streifen unterscheiden, die an der Seite des Körpers zusammenfliessen. Zwischen der Mittellinie der Seite und der vorderen Seitenlinie ein dunkler Fleck, der ungefähr im 4ten Querstreifen liegt. Er ist doppelt so weit von der Basis der Schwanzflosse wie von der Spitze des Kiemendeckels entfernt. Ein dunkler Streifen geht von dem Auge aufwärts nach oben und hinten und nähert sich im Nacken dem der anderen Seite, ohne sich jedoch mit ihm zu vereinigen. Ein anderer dunkler Streifen geht von dem Auge abwärts und etwas nach hinten über die Backe. Die Rückenflosse zeigt 2 bis 3 undeutliche Streifen parallel der Basis. Die Schwanzflosse hat deren $4-5$.

Das grösste unter 5 Exemplaren ist (ohne Schwanzflosse) $34 \mathrm{Mm}$. lang, und $14 \mathrm{Mm}$. hoch. Aus kleinen Tümpeln bei Porto Alegre.

17. Heros acaroides n. sp.

D. ${ }^{16} / 9$. A. ${ }^{6-7 / 8}$. L. lat. 26 .

Auf den Backen 4-5 Schuppenreihen. Umschlag der Unterlippe in der Mitte unterbrochen. Ursprung der Bauchflossen nur sehr wenig hinter dem vorderen Ende der Rückenflosse. Die Breite des Praeorbitale nur wenig kleiner als der Durchmesser des Auges, Entfernung der Augen voneinander etwas grösser als dieser. Höhe etwas mehr als $2 \mathrm{mal}$ und Länge des Kopfes fast $3 \mathrm{mal}$ in der Länge des Körpers (ohne Schwanzflosse) enthalten. Der Raum zwischen Rücken- und Schwanzflosse gleich der halben Höhe des freien Theiles des Schwanzes. Farbe hell grün, mit $6-7$ schwarzgrünen Querbändern. Das 3te (oder 4te?) hat unter der Seiten- 
linie eine dunklere Stelle, die bei ausgebleichten Exemplaren wie ein Seitenfleck erscheint. An der Basis der Schwanzflosse bildet das letzte Querband iiber der Seitenlinie gleichfalls einen etwas dunkleren Fleck. Unter 4 Exemplaren ist das grösste ohne Schwanzflosse $73 \mathrm{Mm}$. lang. Bei Porto Alegre in stagnirenden Gewässern. Ich würde die Art unbedingt für H. autochthon Gnthr. gehalten haben, doch unterscheidet sie sich von diesem durch die zahlreicheren und kleineren Schuppen der Backen.

Eine Anzahl junger Individuen (ohne die Schwanzflosse) nicht über $20 \mathrm{Mm}$. lang ist zwar im Spiritus sehr ausgebleicht, allein die Querbinden sind doch ziemlich deutlich zu erkennen, ebenso der schwarze Seitenfleck, der sich von der Schwanzflosse aus gezählt auf der 4ten Querbinde befindet, wenn die dunkle Stelle an der Basis der Schwanzflosse als 1te Binde gezählt wird.

\section{Heros sp.?}

Ein einzelnes Exemplar eines Heros aus dem Rio Cadea, dem vorigen sehr ähnlich gefärbt, aber viel niedriger im Verhältniss zur Länge, ist zu schlecht erhalten, um noch die Species mit Sicherheit bestimmen zu körnen. Namentlich ist auch die Rückenflosse, wahrscheinlich durch eine früher erhaltene Wunde, etwas defect, so dass sich die Zahl ihrer Strahlen nicht genau ermitteln lässt.

19. Crenicichla lepidota Heck. 1. c. p. 429.

D. ${ }^{17}-18 / 14^{-15}$. A. $3 / 9$. L. lat. $45-47$.

Diese Art, welche von Günther (Catal. of the Fishes etc. Vol. IV, p. 308) mit C. saxatilis vereinigt wird, scheint mir doch von dieser verschieden zu sein. Ich erhielt nämlich theils aus dem Rio Cadea des Urwaldes, theils aus dem Guahyba bei Porto Alegre 7 Exemplare einer Crenicichla, auf welche die von Heckel l. c. gegebene Beschreibung seiner C. lepidota sehr gut passt. Namentlich charakteristisch ist die geringe Anzahl der Schuppenreihen, die bei Heckel für C. lepidota nur 44 beträgt, so dass diese Art unter allen derselben Gattung 
die grössten Schuppen besitzt. Für C. saxatilis giebt H e ckel l. c. p. 432 zwar dieselbe Zahl an, ohne jedoch seine Quelle dafür zu nennen. Da Heckel nach der Beschreibung neuer Arten der Gattung Cichla l. c. p. 415 auch die schon bekannten mit der Bemerkung "von uns nicht gesehene Arten" aufführt, eine solche Notiz aber 1. c. p. 432 bei Aufzählung der schon bekannten Crenicichlen fehlt, so könnte man annehmen $\mathrm{Heckel}$ habe die beiden Arten C. saxatilis und labrina selbst vor sich gehabt; allein dann ist es auffallend, dass er nur für die Erstere eine genaue Aufzählung der Flossenstrahlen und Schuppen giebt, für die Letztere aber nicht. Eine Aufklärung dieser Verhältnisse ist um so wünschenswerther, als die Angaben in Güntber's Fischcatalog p. 308, sehr abweichend sind. Hier werden nämlich der C. saxatilis 54 Schuppenreihen zugeschrieben. Es ergiebt dies eine Differenz, welche bei den Crenicichlaarten mit vielen Schuppenreihen wie C. Johanna etc. nicht auffallend wäre, bei C. lepidota und C. saxatilis aber ausser den Grenzen des Variirens zu liegen scheint. An einem Exemplar der C. saxatilis der Bloch'schen Sammlung (Berl. zool. Mus. Nr. 843) wahrscheinlich das Original zu der Abbildung der Perca saxatilis hei Bloch Taf. 309, zähle ich 58 Querreihen der Schuppen ${ }^{1}$ ), welche Zahl mehr mit den Angaben bei Günther als mit denen bei Heckel übereinstimmt.

Ein kleines Exemplar, $23 \mathrm{Mm}$. lang, welches bei Porto Alegre gesammelt wurde, stimmt in der Zahl der Flossenstrahlen und Schuppenreihen mit C. lepidota überein, darf also wohl als ein Jugendzustand dieser Art angesehen werden. Die Oberseite ist (in Spiritus) hellbräunlich, die Unterseite weiss. Auf der Grenze beider geht ein dunkler Streifen vom Oberkiefer anfangend durch das Auge bio zur Basis der Schwanzflosse und

1) Die citirte Abbildung zeigt nur etwa 48 Querreihen; sie ist auch sonst ungenau, da sie die Schuppen der Seitenlinie nur so gross darstellt wie die übrigen Schuppen, während sie in Wirklichkeit grösser sinà. 
lässt sich auch noch auf dieser bis zu ihrem Hinterrande verfolgen. Auf der Rückenseite kann man noch 2 sehr feine und undeutliche Streifen unterseheiden, deren oberer unmittelbar an der Rückenkante, deren unterer zwischen ihm und dem dunklen Seitenstreifen von vorn nach hinten verläuft. Das Profil des Rücken erscheint etwas gewölbt und ist am Ursprung der Rückenflosse am höchsten.

20. Crenicichla punctata n. sp.

$$
\text { D. }{ }^{22} / 12 \text {. A. } 3 / 10 \text {. L. lat. } 64-67 \text {. }
$$

Der senkrechte Durchmesser des Auges $1 \frac{1}{2} \mathrm{mal}$ in der Entfernung der Augen von einander, diese $3 \frac{1}{2}$ in der Kopflänge (vom Oberkiefer aus gemessen), diese $31 / 4 \mathrm{mal}$ in der Körperlänge (ohne Schwanzflosse) enthalten. Die Unterseite (in Spiritus) ist ron der Mittellinie abwärț hell bräunlich, die Rückenseite dunkler "braun mit ungefähr 7 dunklen Querbinden, welche nur bis zur Mittellinie herabgehen, hier aber am dunkelsten sind. Bei dem kleineren Exemplare sind diese Bänder nach dem Rücken zu fast verschwunden, die unteren Enden dagegen zu einem dunkeln mehr oder weniger zusammenhängenden Längsbande vereinigt, welches sich oberhalb der Mittellinie rom Kopf bis zur Basis der Schwanzflosse erstreckt. Im Leben ist die Grundfarbe gelblich grün mit dunkelgrünen Zeichnungen. Auf der Basis der Schwanzflosse oberhalb der Mittellinie ist ein runder schwarzer Fleck. Ein dunkelbraunes Band geht von dem unteren Rande der Orbita schräg nach abwärts über die Backen, soweit diese beschuppt sind. Ein anderer aber nicht so deutlicher Fleck befindet sich dicht hinter dem Auge. Die ganze Oberseite des Thieres ist mit dunkeln Punkten besäet, die aber nicht so gross und zahlreich wie bei C. polysticta sind. Auch fehlen sie auf einem bedeutenden Theile der Unterseite, da sie sich wenig unter die Mittellinie erstrecken. Die verticalen Flossen hell mit wenigen feinen Punkten zwischen den Strahlen. Die Brust- und Bauchflossen sind ganz weiss und ohne Punkte. Die Schwanzflosse ist etwas weniger beschuppt als bei der folgenden Art. Von dieser unterscheidet sie 
sich durch die geringere Zahl der Querbänder und durch die feineren und minder zahlreichen Punkte. Sowohl aus dem Guahyba bei PortoAlegre wie aus den Bächen des Urwaldes. Das grössere Exemplar hat eine Länge (ohne Schwanzflosse von der Oberlippe an gemessen) von $148 \mathrm{Mm}$.

Drei kleinere Exemplare von 76, 91 und $104 \mathrm{Mm}$. Länge aus den Waldbächen von der deutschen Colonie Sta. Cruz in Rio Grande do Sul sind, obgleich sehr gut erhalten, durch einen eigenthümlichen Zersetzungsprozess des Spiritus, in dem sie anfangs lagen, ganz braun geworden, lassen aber doch noch die dunkeln Punkte, und das grösste Exemplar auch noch eine Spur der dunkeln Zeichnung erkennen, so dass sie wohl ohne Bedenken zu dieser Spccies gezogen werden können.

In demselben Bach, welcher diese drei Exemplare lieferte, wurden ausserdem 6 kleine Individuen gefangen, welche unsre Art im Jugendzustand vorstellen und mit ihr in der Zahl der Flossenstrahlen und Schuppenreihen übereinstimmen. Sie sind höchstens $29 \mathrm{Mm}$, lang und unterschieden von den Jungen der vorhergehenden Art sogleich durch ibre ganz walzenförmige Gestalt. Ihre Unterseite ist auch etwas weniger weiss, und der branne Seitenstreif enthält auf der Basis der Schwanzflosse einen schwarzen Fleck. Auf der Rückenseite lassen sich 7-8 etwas dunkle Querbänder unterscheiden, die in dem braunen Seitenstreifen endigen.

21. Crenicichla polysticta n. sp. D. ${ }^{20} 22 / 12$. A. $3 / 10$. L. lat. 70 .

Der senkrechte Durchmesser des Auges ist ungefähr $21 / 4 \mathrm{mal}$ in der Entfernung der Augen voneinander, diese $4 \mathrm{mal}$ in der Länge des Kopfes (vom Oberkiefer aus gemessen), diese 3 mal in der Länge des ganzen Thieres (ohne Schwanzflosse) enthalten. Die Farbe (in Spiritus) ist an der ganzen Unterhälfte hellgrau, die Rückenseite ist dunkler und zeigt ungefähr 10-11 schwärzliche Querbinden, die nur bis zur Mittellinie herabgehen, hier aber am dunkelsten und so breit sind, dass oft $z w e i$ benach- 
barte zusammenfliessen. Wenn durch die Einwirkung: des Spiritus die Rückenseite heller geworden ist, dann erscheinen die unteren Enden dieser Querbänder deutlicher und gleichen mehr einzelnen Flecken. Ein schmaler dunkler Streifen geht vom unteren Rande der Orbita schräg nach unten und hinten, soweit die Backen beschuppt sind. Ein sehr undeutlicher wenig dunkler Fleck befindet sich auch unmittelbar hinter dem Auge. Ausserdem ist das ganze Thier mit schwärzlichen Punkten besät, die nur die Unterseite des Bauches, vom Kinn bis zum After frei lassen, auf den dunkeln Theilen der Rückenseite verschwinden, an dem Kopf aber am grössten sind und hier als kleine runde Flecke erscheinen. Auch alle verticalen Flossen sind zwischen den Strahlen auf hellem Grunde mit diesen Punkten versehen. Die Brust- und Bauchflossen sind einfarbig hell oder haben nur wenige und undeutlichere Punkte. Im Leben ist der helle Grund gelblich grün, die dunkleren Stellen sind dunkelgrün. Die Schwanzflosse ist zwischen den Strahlen beschuppt, am oberen und unteren Rande über die Hälfte hinaus, in der Mitte etwas weniger. Drei grosse Exemplare sind (ohne Schwanzflosse) $225 \mathrm{Mm}$. lang. Ein kleineres Individuum von $120 \mathrm{Mm}$. Länge zeigt dieselben Zeichnungen wie die grösseren Exemplare. In Rio Cadea des Urwaldes von Rio Grande do Sul.

In der Mundhöhle des Fisches lebt ein noch unbeschriebener Argulus.

22. Geophagus brasiliensis Kner. Novara Exp. Fische, p. 266, Taf. X Fig. 3.

D. ${ }^{1}-415 / 11^{-12}$. A. $3 / 8$.

Unter 4 Exemplaren dieser Art sind die beiden kleineren (ohne Schwanzflosse) $131 \mathrm{Mm}$. und $99 \mathrm{Mm}$. lang aus einem kleinen Teiche im botanischen Garten bei Rio de Janeiro, die beiden grösseren, $163 \mathrm{Mm}$. und $143 \mathrm{Mm}$. lang, aus Porto Alegre. Im Leben schillern die Seiten des Körpers und der Rücken im schönsten Blaugrün und sind mehr oder weniger deutlich mit kleinen silberglänzenden Flecken bestreut. 
Von Gün the r (Catal. Fish. IV 1862, p. 312) ist eine besondere Gattung, Satanoperca, für die Geophagusarten errichtet worden, bei denen die Basis des weichen Theiles der. Rückenflosse unbeschuppt ist. Es würde dann der G. brasiliensis in diese Gattung gehören. Allein es finden sich zwischen den Arten mit nackter und denen mit beschuppter Basis der Rückenflosse so allmähliche Uebergänge, dass eine strenge Unterscheidung der beiden Gattungen nicht auszuführen ist.

\section{Geophagus rhabdotus n. sp.}

$$
\text { D. }{ }^{14} / 9 . \text { A. } 3 / 8 \text {. L. lat. } 26 .
$$

Backen mit ungefähr 4 Schuppenreihen. Breite des Pracorbitale etwas grösser als der Durchmesser des Auges. Der Umschlag beider Lippen nicht gross, in der Mitte unterbrochen. Die Seiten des Rumpfes mit hell silberglänzenden Längsstreifen und dazwischen liegenden, schmäleren dunkeln. Die verticalen Flossen grau mit feinen hellen Streifen.

Die Höhe ist $2^{1 / 3} \mathrm{mal}$, die Länge des Kopfes $2^{2} / 3 \mathrm{mal}$ in der Länge des Körpers (ohne Schwanzflosse) enthalten. Die Entfernung der Augen von einander gleich der Breite des Praeorbitale. Ein schmales dunkles Band beginnt auf dem Hinterkopf und geht abwärts über das Auge und die Backen. Mehrere etwas dunkle aber sehr undeutliche Querbänder gehen von dem Rücken nach dem Bauche. Etwa im 3ten derselben unterhalb der Seitenlinie ein grosser schwärzlicher Fleck, ungefähr in der Mitte zwischen Kopf und Schwanzflosse, aber zwischen der mittleren Höhe der Körperseite und der Seitenlinie. Charakteristisch ist die Färbung der Seiten auf denen helle silberglänzende Längsstreifen mit schmäleren dunklen abwechseln. Diese gehen über die Mitte der Schuppen, jene über die Seiten derselben. Bei G. brasiliensis Kn. und G. gymnogenys findet sich oft eine ähnliche Zeichnung, allein dann werden die hellen Längsstreifen von einzelnen silberweissen Flecken zusammengesetzt, die sich auf der Mitte jeder Schuppe befinden, aber nicht den freien Rand derselben erreichen, während die Seiten der 
Schuppen dunkel sind. Die Brustflossen, welche bis zum Anfang der Analflossen hinausreichen, sind weiss, die übrigen grau, am dunkelsten die Ventralflossen, welche nur bei den grösseren Exemplaren mit ihren Spitzen die Basis der Ventralflosse erreichen. Die hellen Streifen auf den verticalen Flossen sind sehr schmal, im Allgemeinen nur halb so breit, wie die dunklen Zwischenräume. An der Rückenflosse gehen sie von deren Basis schräg nach hinten und oben, so dass die, welche am Fusse des 11 ten und 12 ten Stachels entspringen, die äusserste Spitze des weichstrahligen Theiles erreichen. Die übrigen Streifen sind diesen mehr oder weniger parallel. An der Caudalflosse sind sie unregelmässiger, etwo so breit wie die dunklen Zwischenräume, und gehen schräg über die Flosse, ungefähr horizontal wenn diese ausgebreitet ist. An der Analflosse gleichen sie denen der Rückenflosse, sind aber undeutlicher. Schwanzflosse an der Basis wenig beschuppt, Rücken-und Afterflosse sind nackt.

Unter vier Exemplaren ist das grösste (ohne Caudalflosse) $82 \mathrm{Mm}$. lang. Aus dem Rio Cadea.

24. Geophagus gymnogenys n. sp.

D. ${ }^{13}-14 / 10$. A. $3 / 8$. L. lat. 27.

Die Backen und Praeoperculum ganz nackt. Umschlag der Ober- und Unterlippe in der Mitte unterbrochen. Breite des Praeorbitale $1 \frac{1}{2} 2$ des Augendurchmessers. Rückenscite dunklerblaugrün schillernd, Unterseite hell. Jede Schuppe der Seiten des Rumpfes mit einem silberweissen Fleck, ein schwärzlicher Streifen verbindet die Augen mit einander und erscheint noch als dunkler Fleck auf den Backen. Ein zweiter breiter Streifen beginut auf dem Rücken vor der Rückenflosse, und endet hinter dein oberen Ende des Operculum unterhalb der Seitenlinie. Ein dritter Streifen beginnt in der Mitte der Rückenflosse, ist hier aber wenig deutlich, bildet jedoch unterhalb der Seitenlinie einen sehr dunklen Fleck. Rückenflosse grau, in ihrem vorderen Theile, der die Stacheln enthält, mit schmalen weissen Streifen, die sich vor der Basis beginnend, nach hinten und oben zie- 
hen und sich lauf dem Theile mit weichen Strahlen in einzeine runde. Flecken auflösen. Schwanzflosse am oberen und unteren Rande fein beschuppt, in der Mitte nur an der Basis, sonst grau mit weissen Flecken. Afterflosse ein wenig grau, am Rande dunkler, an der Basis heller, in ihrer basalen Hälfte mit rundlichen weissen Flecken. Bauchflossen dunkelgrau oder weiss, erreichen mit ihren Spitzen die Basis der Analflosse. Die Brustflossen weiss, gehen bis hinter den Anfang der Analflosse.

Bei diesen Fischen scheint ein Geschlechtsunterschied in der Bildung des Kopfes zu bestehen. Einige Exemplare besitzen auf dem Hinterkopf eine Anschwellung, welche sich bis auf die Stirn zwischen den Augen erstreckt, und vielleicht aus einer fetthaltigen gallertartigen Masse besteht. Sie hat Schuppen, da diese bis zu den dunklen Streifen gehen, der die Augen miteinander verbindet. Diese Anschwellung findet sich bloss bei einigen Individuen, wahrscheinlich den alten Männchen in der Laichzeit, bei allen jungen Individuen fehlt sie, auch bei einigen grösseren, wahrscheinlich den Weibchen. Ist die Anschwellung sehr entwickelt. so geht ein dunkler fast schwarzer Längsstreifen über ihre obere Kante, der das erste Querband mit dem zweiten verbindet. An den Exemplaren ohne Anschwellung sind Analflosse und Bauchflosse hell, doch zeigt die erstere immer noch die weissen Flecke. Die Zähne sind fein, hechelförmig, vorn etwas grösser und kegelförmig, an den Spitzen etwas braun. Bei einzelnen Exemplaren finden sich unter dem Auge auf den Backen einige vereinzelte Schuppen vor. Der Kiemendeckel ist in seinem mittleren Theile schuppenlos. Auch die Rücken- und Analflosse sind ganz nackt. An den kleineren Exemplaren lassen sich namentlich auf der Rückenseite noch einige unbestimmte und verwaschene dunklere Querbänder sehen, das dritte dunkle Querband bildet bei den mit Anschwellung versehenen Exemplaren ein dunkler Fleck auf der Mitte der Seite, der die 9te und 10te Schuppe der Seitenlinie und je drei Schuppen der zwei darunter liegenden Längsreihen umfasst. Die Höhe des Körpers am Anfang der Rücken- 
flosse ist $2^{1 / 2}$ mal und die Länge des Kopfes reichlich $3 \mathrm{mal}$ in der Länge des Körpers (ohne Schwanzflosse) enthalten.

Der Darmkanal enthält stets nur die zerbrochenen Schalen der jungen Cyrena limosa Mat. 1), welche die Thiere aus dem Schlamm der Gebirgsbäche aufnehmen, ohne jedoch diesen selbst zu verzehren. In Gebirgsbächen des Urwaldes von Rio Grande do Sul.

25. Geophagus bucephalus n. sp.

D. ${ }^{14} / 10$. A. $3 / 8$. L. lat. 29 .

Backen mit ungefähr fünf Schuppenreihen. Lippenumschlag ausserordentlich entwickelt. Der obere in der Mitte am grössten, so gross wie der Durchmesser des Auges, der untere ihm gleich, in der Mitte durch einen tiefen Einschnitt, der aber nicht die Basis erreicht, halbirt. Auf der Stirn eine grosse, gallertartige Anschwellung, welche bis zu einer Linie herabsteigt, die die Nasenlöcher mit einander verbindet. Das Praeorbitale doppelt so breit wie das Auge. Farbe blaugrün, auf der Oberseite dunkel, unten hell. Jede Schuppe mit einem hellen silberglänzenden Fleck, der freie Rand aber dunkel. Auf der Mitte der Seite zwischen Mittel- und Seitenlinie ein dunkler Fleck, da hier der freie Rand der Schuppen besonders dunkel und der helle Fleck kleiner ist.

Die Körperform lang gestreckt. Die Höhe $2^{3} /{ }_{4} \mathrm{mal}$, die Länge des Kopfes etwas mehr als 3 mal in der Körperlänge (ohne Schwanzflosse) enthalten. Die Rückenflosse verhältnissmässig niedrig, der 8te Stachel derselben gleich $11 / 3$ mal dem Durchmesser des Auges. Alle Flossen grau, die Brustflossen am hellsten, die Bauchflossen am dunkelsten. Rüickenflosse mit einigen breiten weissen Streifen, die im stacheltragenden Theil vorzugsweise am freien

1) Hr. v. Martens hatte sie in der Bearbeitung der von mir in Südbrasilien gesammelten Land- und Süsswassermollusken (Malak. Blätt. 1868. V. p. 202) als C. variegata Orb. bezeichnet. Später hat derselbe jedoch Gelegenheit gehabt, sich zu überzeugen, dass diese Art mit der älteren C. limosa Mat. identisch ist. 
Rande und diesem ziemlich parallel, im binteren Theile dagegen mehr den Strablen parallel gehen. An der Schwanzflosse hat sich das Weiss auf der ganzen Flossenhaut so ausgebreitet, dass nur am oberen und unteren Rande das Grau der Grundfarbe in einigen Flecken auftritt. Auf der Analflosse befinden sich statt der Streifen rundliche helle Flecke. Die Bauchflossen erreichen mit ihren Spitzen kaum die Basis der Analflosse. Der freie Theil des Schwanzes sehr lang, fast so lang wie die Schwanzflosse, welche in der Mitte ein wenig ausgeschnitten ist. Rücken- und Analflosse erreichen angedrückt die Basis der Schwanzflosse. Sie sind ganz nackt, die Letztere dagegen an der Basis beschuppt und zwar in der Mitte sehr wenig, am oberen und unteren Rande mehr, fast bis zur Hälfte.

Drei grosse Exemplare von $137 \mathrm{Mm}$. Körperlänge (ohne Schwanzflosse) besitzen die grösste Anschwellung des Kopfes, die hier die Verticallinie der Schnauzenspitze erreicht. Bei einem 4ten Exemplar, fast ebenso lang und zu derselben Zeit gefangen, und bei einem 5ten, $111 \mathrm{Mm}$. lang, ist die Anschwellung nur ganz unbedeutend. Auch sieht man noch eine Spur davon an einem $93 \mathrm{Mm}$. langen Individuum. Dagegen fehlt sie ganz bei zwei 72 und $68 \mathrm{Mm}$. langen Individuen. Auch ist hier die Entwicklung der Lippen geringer als bei den grossen Exemplaren. Die Breite des Praeorbitale ist ebenfalls vom Alter abhängig, denn bei dem kleinsten Individuum ist sie nur wenig grösser als der Durchmesser des Auges. Aus dem Rio Cadea und seinen Zuflüssen.

26. Geophagus labiatus n. sp. D. ${ }^{14} / 10$. A. ${ }^{3} / 8$. L. lat. 28.

Die Beschuppung der Backen ist unvollständig; in vier Reihen geordnet bedecken die Schuppen nur die oberen $2 / 3$ der Backen. Die Lippen sehr entwickelt, ähnlich wie bei G. bucephalus. Ihr Umschlag oben und unten vollständig, nur an der Unterlippe zeigt er in der Mittellinie einen tiefen Einschnitt ungefähr bis zu seiner halben Breite. 
Die Breite des Praeorbitale ungefähr $13 / 5 \mathrm{mal}$ den Durchmesser des Auges. Die Höhe des Körpers $2^{1} / 2 \mathrm{mal}$, die Länge des Kopfes $3 \mathrm{mal}$ in der Länge des Körpens (ohne Schwanzflosse) enthalten. Zwischen den Augen befindet sich eine unbedeutende Anschwellung die aber im Spiritus sehr eingeschrumpft ist. Die Rückenflosse niedrig, ihr 8 ter Stachel ungefähr $1 \frac{1}{2}$ mal den Durchmesser des Auges. Alle Flossen hell. Auf dem hintersten Theil der Rückenflosse einige weisse Flecke angedeutet. An der Schwanzflosse die Flossenhaut zum grossen Theile weiss, nur an der Basis unregelmässig grau gezeichnet. An der Afterflosse die weissen Flecke ziemlich deutlich. Die Farbe (im Spiritus) gelblich braun, unten heller, oben dunkler, jede Schuppe der Seiten mit einem un deutlichen Silberfleck. In der Mitte des Körpers unterhalb der Seitenlinie ein dunkler Fleck, unmittelbar hinter ihm ein anderer weniger deutlicher. Die Rücken- und Afterflosse nackt, die Schwanzflosse an der Basis deutlich beschuppt, in der Mitte weniger, am oberen und unteren Rande über deren Mitte hinaus. Von G. bucephalus unterscheidet sich die Art besonders durch die viel bedeutendere Höhe des Körpers.

Das einzige Exemplar, von $145 \mathrm{Mm}$. Körperlänge (ohne Schwanzflosse) fand sich im Rio Santa Maria des Urwaldes von Rio Grande do Sul.

27. Geophagus scymnophilus n. sp. D. $14 / 10$. A. $3 / 8$. L. lat. 28.

Auf den Backen 4-5 Reihen zum Theil etwas unregelmässig geordneter Schuppen, die nur die oberen $2 / 3$ derselben bekleiden. Das Praeorbitale bei den grösseren Exemplaren nur wenig schmäler als das Auge. Der Umschlag der Lippen mässig entwickelt (mehr als bei G. brasiliensis $\mathrm{Kn}$. oder G. gymnogenys und weniger als bei G. labiatus oder G. bucephalus), in der Mitte der Unterlippe mit einem Einschnitt, der aber nicht bis auf die Basis reicht. Eine Anschwellung der Stirn ist nicht vorhanden. Die Farbe der in Spiritus aufbewahrten Exemplare ist hell bräunlich gelb, mit dunkleren Zeich- 
nungen, welche in Gestalt von undeutlichen und unregelmässigen Querbändern auf den Seiten verlaufen und den Rücken dunkler färben als die Bauchseite, welche nach unten hell silberfarben wird. Das dunkle Querband, welches etwa der Mitte der Rückenflosse entspricht, enthält einen runden, schwarzen Fleck, der dicht unter der Seitenlinie liegt. Als erstes Querband kann man einen dunkeln Streifen betrachten, der im Genick nahe vor dem Anfang der Rückenflosse entspringt und schräg nach vorn und abwärts gegen das Auge verläuft, um über dasselbe und darauf über die Backen fast senkrecht abwärts zu gehen. Dieser Streifen ist hier dunkler als die Zeichnungen der Körperseiten aber heller als der Seitenfleck. Die Flossen sind hell, ungefleckt und nur wie gewöhnlich mit den feinen Pigmentpünktchen besäet. Die Brustflossen erreichen mit ihren Spitzen die Vertical-Linie des Anfangs der Analflosse, die Bauchflossen reichen nicht so weit. Rücken- und Analflossen erreichen mit ihren Spitzen nicht die Basis der Schwanzflosse. Höhe $2^{2} /{ }_{3}$ mal, Kopflänge $3 \mathrm{mal}$ in der Körperlänge (ohne Schwanzflosse) enthalten, die bei dem grössten unter 9 Exemplaren $66 \mathrm{Mm}$. beträgt.

Diese Species, welche nicht grösser wird, als das angegebene Mass beträgt, ist schon dadurch hinreichend von G. gymnogenys und G. bucephalus unterschieden, sie gleicht aber sehr den jungen Individuen dieser beiden Arten. Namentlich ist sie ganz so gefärbt und gezeichnet wie der G. gymnogenys in der Jugend, auch die Proportionen des Körpers stimmen dann überein, allein durch die einfarbigen Flossen, die beschuppten Backen und den entwickelteren Umschlag der Lippen ist sie leicht von dieser Art zu unterscheiden. Von dem G. bucephalus im Jugendzustande ist sie unterschieden durch die bedeutendere Höhe des Körpers und die etwas geringere Höhe des Schwanzes dicht vor der Caudalflosse. Auch ist schon bei dem jungen G. bucephalus der Lippenumschlag stärker entwickelt.

Die Gattung Geophagus ist durch höchst merkwürdige Eigenthümlichkeiten in ihrer Brutpflege bekannt, 
und zwar scheint es das männliche Geschlecht zu sein, welches sich durch eine besondere Aufmerksamkeit für die Brut auszeichnet. Ich habe Gelegenheit gehabt, A ehn * liches auch bei $G$. scymnophilus zu beobachten. Leider war der Sommer schon zu weit vorgerückt (December), um das Laichen selbst zu sehen. Ich muss es daher un entschieden lassen, ob der Fisch ein besonderes Nest baut, oder ob er die Eier in der Mundhöhle ausbrütet. Dagegen gelang es mir sehr häufig, die Sorgfalt zu beobachten, mit welcher das Thier, wahrscheinlich das Männchen, die Jungen beschützt und leitet. Zu der Zeit, in welcher diese noch sehr klein sind, hält sich der alte Fisch in den seichten Gebirgsbächen auf, wo das Wasser hell und rein über die Geschiebe dahin fliesst, und wo er auch wahrscheinlich laicht. Hier nun findet man ihn an besonders flachen Stellen in der Nähe des Ufers, wo das Wasser durch locale Hindernisse aufgehalten, ganz ruhig erscheint, wo die Steine mit grünen Algen überzogen sind und der Boden reichlich mit Schlamm bedeckt ist. Hier schwimmt die Heerde der Jungen vielleicht aus 20-30 Stück bestehend sorglos umber, während der Alte in einer Entfernung vorsichtig Wache hält. Zeigt sich nun irgend eine Gefahr z. B. ein plötzlich herantretender Mensch, so erscheint der Alte schnell unter der Heerde und giebt ihr wahrscheinlich ein Zeichen. Alle Jungen versammeln sich wie auf Commando an dem Maule des Alten, das sie wie ein Bart umgeben, blitzschnell verschwinden sie alle zusammen in ihm, und ehe man es hindern kann, hat sich der Alte weit mit ihnen entfernt. Behält man ihn im Auge, so sieht man wie er bald eine Stelle, ähnlich der verlassenen aufsucht und hier seine Jungen aus ihrem Gewahrsam wieder entlässt.

Hat man den Fisch von weitem beobachtet, was bei der Klarheit des Wassers leicht ist, so gelingt es nicht selten durch Vorsicht so nahe heran zu kommen, dass man durch schnelles Zufahren, mit einem Netz z. B., zwischen den Alten und seine Jungen gelangt, und diese in der Bucht isolirt. Sie schwimmen dann in einen Haufen zusammengedrängt in dem kleinen, ihnen übrig gebliebenen 
Raume hin und her und harren der Hilfe des Alten, während dieser ausserhalb unruhig auf eine Lücke lauert, durch die er seine Jungen entführen kann. Er vollführt das so schnell und vorsichtig, dass es mir trotz aller Mühe niemals gelungen ist, ihn mit den Jungen im Maule durch das Netz zu fangen. Erst dadurch, dass auf seiner Flucht dicht neben ihn ein starker Schuss in's Wasser abgefeuert und er auf diese Weise getödtet oder betäubt wurde, gelang es mir ein Exemplar mit der Brut in der Mundhöhle zu erhalten. Die Jungen liegen darin dicht gedrängt, mit den Köpfen nach den Kiemen hin gerichtet.

\section{Geophagus pygmaeus n. sp.}

D. ${ }^{14} / 10$. A. $3 / 8$. L. lat. 27 .

Der Mund klein und spitz, etwas vorgestreckt. Der Körper stark seitlicb zusammengedrückt, mit fünf dunklen Querstreifen, welche in der Mittellinie und an der Rükkenkante am dunkelsten sind. Lin dunkler Fleck im Nacken, ein ziemlich deutlicher grauer Streifen von dem Auge nach dem Winkel des Praeoperculum. Die Backen sowie der ganze Kiemendeckel ohne Schuppen.

Die Höhe des Körpers beträgt $1 / 3$ seiner Länge (ohne Schwanzflosse). Die Augen sind gross, ihr Durchmesser gleich $1 / 3$ der Höhe und gleich der Höhe des Schwanzes vor der Basis der Schwanzflosse. Das Praeorbitale schmal, nur halb so breit wie der Durchmesser des Auges. Die Breite der Stirn zwischen den Augen beträgt nur $2 / 3$ des Durchmessers derselben. Die Länge des Kopfes ungefähr gleich der Höhe des Körpers oder nur sehr wenig grösser. Die Lippen gewöhnlich, ohne besondere Faltenbildung. Die Zähne klein, hechelförmig. Der Anhang des äusseren Kiemenbogens sehr deutlich. Die Flossen sind farblos. Die Grundfarbe im Leben hell grünlich gelb, die Streifen bräunlich grün. Das grösste unter fünf Exemplaren hat eine Länge (ohne Schwanzflosse) von $23 \mathrm{Mm}$. Dieses kleine Fischchen lebt in Guahyba bei Porto Alegre, zwischen dichten Wasserpflanzen. Es 
findet sich nur einzeln und weiss sich den Nachstellungen durch grosse Schnelligkeit zu entziehen.

29. Pimelodus maculatus Lacép.

Dieser von den Brasilianern seiner hübschen Färbung wegen "Pintado" genannte Fisch lebt sebr häufig im Jacuby und seinen Zuflüssen, doch geht er nicht in's Gebirge hinauf. Der erste Strabl seiner Brustflossen gilt als giftig, daher auch kein Exemplar auf den Markt gebracht wird, dem nicht dieser Stachel vorher abgebrochen worden ist.

30. Pimelodus sapo? Val. (d'Orb. Voy. Amér. Mérid. Poiss. pl. 2. Fig. 6-8).

Die mir vorliegenden Exemplare, vier grössere, und sechs kleinere, haben D. $1 / 7$ und A. 12, eins der grösseren hat D. $1 / 8$, A. 11. Sie vereinigen also die Charaktere des P. sapo und P. Hilarii Val., welcher D. 1/8 A. 12 haben soll (Hist. Nat. Poiss. XV. p. 180). Der Oberkiefer überragt bei allen ein wenig den Unterkiefer. Die Barteln variiren in der Länge. Bei kleinen Individuen reichen sie bis zur Mitte der Fettflosse, bei den grössten nur bis zum Ende der Rückenflosse. Es fragt sich daher, mit welcher der beiden genannten Arten wir es hier zu thun haben, und ob nicht diese vielleicht in eine zusammengezogen werden müssen. Der Durchmesser der Augen ist bei dem grössten Exemplare, welches (ohne Schwanzflosse) ungefähr $325 \mathrm{Mm}$. lang ist, gleich $1 / 4$ des Abstandes der Augen von einander. Die Brasilianer nennen den Fisch Jundiá. Er lebt im Guahyba und seinen Zuflüssen und geht selbst bis zum Urwald hinauf. Bei Tage hält er sich in Löchern des Ufers auf und kornmt nur des Nachts zum Vorschein, wo er mit Angeln gefangen wird.

31. Pimelodus lateristriga Müll. Trosch. Hor. Ichth. III. p. 3.

Fünf Exemplare dieses Fisches von Porto Alegre gleichen sehr dem Müller'schen Original-Exemplar im Berliner Zoologischen Museum. Aber alle haben höch- 
stens eine schwache Andeutung des dunklen Seitenstreifens. Die grössten Exemplare sind (ohne Schwanzflosse) $88 \mathrm{Mm}$. lang.

32. Arius Commersonii. (Günther. Cat. Fish. V. p. 143). Pimelodus Commersonii Lacép. Bagrus Commersonii Val. (d'Orb. Voy. Amér. Mérid. Poiss. pl. 3. Fig. 1.)

Er ist einer der grössten und häufigsten Fische des Guahyba und seiner grossen Zuflüsse. Die Oberseite ist bleigrau, die Unterseite weiss. Die Exemplare, welche ich in Rio Grande sah, die also wahrscheinlich aus Brackwasser waren, sahen auf der Oberseite grün aus. Die Brasilianer nennen ihn Bagre (auch Bagadú) und verachten sein Fleisch, welches nach ihrer Ansicht nur für Neger gut ist, daher heisst er auch der "Negerfisch" und ist trotz seiner Grösse der billigste.

Auch bei ihm findet sich die merkwürdige Brutpflege, welche schon von anderen Arius-Arten und Verwandten bekannt ist. Das Weibchen legt ungefähr im September, also im Frühling, nur wenige aber sehr grosse Eier, welche etwa die Grösse gewöhnlicher Flintenkugeln besitzen. Das Männchen befruchtet sie ohne Zweifel zuerst, und nimmt sie darauf in die Mundhöhle, um sie hier sich entwickeln zu lassen. Welche Zeit dazu nöthig ist, blieb mir unbekannt. Ohne Zweifel kann das Männchen unterdess keine Nahrung zu sich nehmen, und da man den Bagre ungemein bäufig todt im Wasser findet, ohne irgend eine Todesursache an ihm wahrnehmen zu können, so ist wohl nicht unwahrscheinlich, dass viele Männchen den Entbehrungen erliegen, die mit dem Brutgeschäft verbunden sind. Oder sollten die Weibchen nur einmal laichen und dann zu Grunde gehen? Leider hatte ich keine Gelegenheit und Zeit, mich über diese Verhältnisse genauer zu unterrichten, da mir die Thatsache zu spät, und nur dadurch bekannt wurde, dass ich einst selbst einen todten Fisch fand, und in der Absicht, ihn nach Wasserinsecten abzusuchen, von allen Seiten besichtigte. Er war noch ganz frisch und unversehrt, und als ich ihm 
zufälligerweise das Maul öffnete, fand ich es ganz angefüllt mit schon sehr entwickelten aber ebenfalls todten Jungen. Dieselben trugen noch den Dottersack in seiner ursprünglichen Grösse. Leider fehlte mir damals die Zeit, weitere Beobachtungen anzustellen, nur erfuhr ich auf meinen Erkundigungen, dass die Fischer in der Laichzeit die männlichen Fische fangen, sie an der Schwanz. flosse in die Höhe heben, und durch Schütteln der Eier in der Mundhöhle berauben. Diese werden gesammelt und getrocknet und später als Köder für die Piaven (Leporinus obtusideus) benutzt. Vielleicht ist auch diese Beraubung die Ursache des Todes der Fische. Wenn man zu rechter Zeit nachsucht, würde man also leicht ein unschätzbares Material für die Entwicklungsgeschichte der Fische sammeln können, da der Bagre häufig ist und in allen Stadien der Foetus ohne Mühe zu erhalten wäre. Auch wïrden sich die Eier ihrer kolossalen Grösse wegen sehr zur Untersuchung eignen.

Wahrscheinlich wird der Bagre nicht bloss die Eier im Maule ausbrüten, sondern auch die Jungen noch eine Zeit lang darinnen beherbergen, so dass man vielleicht aus diesem Vorgange auf Aehnliches bei Geophagus scymnophilus schliessen darf. Vielleicht trägt dieser seine Jungen nicht bloss in der Mundhöhle umher, sondern brütet sie auch darinnen aus.

33. Genidens Cuvieri Casteln. (Bagrus genidens Cuv. Val. XIV. p. 452. pl. 419).

Er kommt gemeinschaftlich mit Pimelodus sapo vor, ist aber seltner. Die Brasilianer unterscheiden ihn nicht von diesem.

Callichthys arcifer (vgl. dies. Arch. XXXIV. Jahrgang 1. Bd. p. 373).

Callichthys hemiphractus (dies. Arch. 1. c. p. 374).

34. Callichthys paieatus Jenyns (Zool. Beagle, Fish. p. 113).

Jenyns unterscheidet 1. c. seine Art von C. punctatus durch das Vorhandensein zweier kleinen Barteln 
an der umgeschlagenen Unterlippe und bezeichnet ausserdem noch die Barteln des Oberkiefers als „haud ultra oculos pertingentibus."

In diesen Punkten stimmen die zahlreichen von mir gesammelten Exemplare mit den von Jenyns beschriebenen überein, doch weichen sie in der Farbe etwas ab, da bei ihnen Brust-, Bauch- und zum Theil auch Analflossen hell, Rücken- und Schwanzflossen aber quergebändert sind.

Das Verhältniss des C. paleatus zu C. punctatus Val. bedarf noch der Aufklärung. Valenciennes hat Exemplare aus Surinam und Montevideo gehabt. Vielleicht gchörten diese letzteren dem C. paleatus an, wenigstens sind die Angaben der Farben bei letzteren übereinstimmend mit dem, was ich an meinen Exemplaren sehe. Bei diesen ist im Leben die Grundfarbe gelb, nach dem Rücken dunkler, nach dem Bauch heller. Alles, was an den Exemplaren in Spiritus dunkel erscheint, ist ein glänzendes Blaugrün. Der Rücken ist unregelmässig gefleckt, an den Seiten kann man drei grosse eckige Flecken unterscheiden. Der erste reicht vom Kiemendeckel fast bis unter das hintere Ende der Basis der Rückenflosse, der zweite kleinere liegt unter dem Anfang der Fettflosse, der dritte kleinste an der Basis der Schwanzflosse. Diese hat 4-5 winklig gebogene Querbänder. Die beiden Rückenflossen haben den Stachel bunt gefärbt, an der ersten derselben besitzt der weiche Theil ein undeutliches Querband, an der zweiten eine dunkle Spitze. Auch die Brust-, Bauch- und Analflossen zeigen bei besonders dunkel gefleckten Individuen je einen grossen dunklen Querfleck in der Nähe der Basis. Unter zahlreichen Exemplaren ist das grösste (ohne Schwanzflosse) $36 \mathrm{Mm}$. lang.

Der Fisch lebt in den umfangreichen Gewässern bei Porto Alegre schaarenweise an seichten Stellen in der Nähe des Ufers. Hier liegt die ganze Schaar in den von der Sonne durchwärmten Schlamm versenkt und erhebt sich bei einer Störung blitzschnell, um sich in der Nähe sogleich wieder herab zu senken und in dem 
Schlamm zu verbergen. Dabei halten sie alle den Rükkenstachel aufgerichtet und können den, der unversehens mit blossen Füssen auf sie tritt, schmerzhaft verwunden.

35. Plecostomus Commersonii (Günther. Cat. Fish. V. p. 232).

Hyportomus Commersonii Val. (d'Orb. Voy. Amér. Mérid. Poiss. p. 7. Fig. 2).

Dieser grösste unter den Panzerwelsen des Jacuhygebietes erreicht eine Länge (ohne die Schwanzflosse) von 4-500 Mm. Doch sind solche Exemplare nicht häufig, oder entziehen sich vielleicht sehr allen Nachstellungen. Die Thiere halten sich am liebsten in seichten Gewässern auf einem Grunde aus grossen Steinen auf, da sie sich hier gut verbergen können und wahrscheinlich an den die Steine überziehenden Algen reichliche Nahrung finden. Wenigstens erzählte mir ein Müller an dem Rio Santa Maria, einem Zuflusse des Rio dos Sinos, dass bei Hochwasser, wenn seine Mühle still stehe, die Cascuden, der brasilianische Name der Panzerwelse, in Menge an das Mühlrad kämen, um das grüne "Moos" von demselben abzufressen. Bei Porto Alegre halten sie sich auch gern an solchen Stellen auf, wo Excremente und überhaupt unreine Stoffe in den Guahyba geschüttet werden. Das Fleisch des Fisches wird nicht geachtet, und höchstens Neger essen ihn, auf dem Markte sieht man ihn niemals.

36. Plecostomus spiniger n. sp.

D. $1 / 7$. A.? L. lat. $27-28$.

Ein trocknes Exemplar aus dem Rio Cadea, welches (ohne Schwanzflosse) $320 \mathrm{Mm}$. lang ist, zeigt folgende Beschaffenheit:

Der Kopf ist flach, vorn elliptisch abgerundet, sehr deutlich granulirt, d. h. durchaus mit kleinen kegelförmigen Spitzen dicht besetzt, wie gepflastert. Am Rande des Kopfes, über dem Auge, und auf der Mitte der Schnauze sind diese Spitzen am dichtesten gedrängt und am längsten, so dass diese Stellen sich auch durch eine 
etwas hellere Farbe vor den übrigen Theilen des Gesichtes auszeichnen. Von jeder Nasengrube aus verläuft über jedem Auge eine undeutliche etwas wulstige Erhabenheit, die zwar schmäler aber deutlicher auch auf dem Temporalschilde zu sehen ist. Auf dem Hinterhaupt ist ein ähnlicher stumpfer und flacher Kiel, ebenfalls durch deutliche Granulirung ausgezeichnet. Er setzt sich als zwei schmale, aber sonst ihm ähnliche Kiele über die drei Schuppen des Nackens fort, nach hinten zu divergirend, und endet allmählich verschwindend auf der getheilten dritten Nackenschuppe zu beiden Seiten des Ursprunges der Rückenflosse. Der Kiel des Temporalschildes wird nach seinem Verschwinden wieder sichtbar auf den nächstfolgenden drei Schuppen, die nach aussen vor den Nak. kenschuppen liegen. An jeder Seite des Körpers lassen sich vier Kiele unterscheiden. Jede Schuppe der Seiten ist fein granulirt, d. h. mit sehr kleinen, zugespitzten kegelförmigen Spitzen besetzt. Aber in der Mitte jeder Schuppe erhebt sich der Kiel, an und für sich unbedeutend aber dadurch sehr kenntlich, dass hier die Spitzen sich zu kleinen Dornen verlängern, die am Hinterende jedes Kielstückes am höchsten sind. Der erste der vier Seitenkiele entspringt um eine Schuppenlänge hinter dem Ursprung der Rückenflosse, ohne jedoch eine unmittelbare Fortsetzung eines. Nackenkieles zu sein. Der 2te Seitenkiel entspringt um eine Schuppenlänge vor dem 1ten, etwas unterhalb des kurzen Kieles, der von dem Temporalschilde herkommt. Der 3te Kiel, der schwächste von allen, entspringt in Gestalt von stärkeren Granulationen und zwei Schuppen vor dem 2ten Kiel, der 4te Kiel endlich entsteht hinter dem Humeralschilde.

Der senkrechte Durchmesser ist etwas grösser als der 4te Theil des Abstandes der Augen von einander. Der Stachel der Rückenflosse ist gleich ihrer Basis, diese ist länger als ihre Entfernung von der Fettflosse, von der sie durch sieben Schuppen getrennt wird. Die Brustflosse erreicht nicht den Ursprung der Bauchflossen. Ihr Stachel ist an der Basis stärker granulirt als der Kopf, nach seiner Spitze zu verwandeln sich auf der Oberseite 
die spitzen Granula in kurze, mehr borstenförmige Dornen, deren längsten etwa gleich dem halben senkrechten Durchmesser des Auges sind. An den Bauchflossen, welche den Ursprung der Analflosse nur wenig überragen, sind die Granula zu kurz, um noch borstenförmig genannt zu werden, obgleich auf der Unterseite in der peripherischen Hälfte viel länger als am Kopf. Zwischen Analund Caudalflosse kann man ungefähr 14 Schuppen oder Schilder zählen. Die Spitzen sind an den beiden Randstrahlen der Letzteren kurz und kaum Dornen zu nennen. Sie sind kürzer als die Dornen an den Brustflossen und länger als die an den Bauchflossen. Auch der Stachel der Fettflosse ist mit Dornen besetzt, die im Allgemeinen denen der Seitenkiele gleichen.

Die Zahl der Zähne ist geringer als bei P. Commersonii, der Umschlag der Unterlippe ist mit kleinen Warzen besetzt, ob er ganzrandig war, lässt sich nicht mehr entscheiden; vielleicht aber vermuthen. Kehle und Bauch, deren Haut zum Theil entfernt ist, sind nach den noch gebliebenen Resten zu urtheilen, ohne Zweifel mit kleinen granulirten Schildern besetzt gewesen.

Die Länge des Kopfes bis zum Ende des OccipitalKieles beträgt $84 \mathrm{Mm}$., seine grösste Breite an den $\mathrm{Hu}$ meral-Schildern $75 \mathrm{Mm}$., die Farbe, so weit sie sich an dem trocknen Exemplar beurtheilen lässt, gleich der der vorhergehenden Art. Die Art hat einige Aehnlickkeit mit Plecostomus (Hypostomus horridus Kner.), allein die Verhältnisse der Rückenflosse, die Form der Bedornung der Seitenschilder und der Schwanzflosse unterscheiden sie hinreichend.

37. Plecostomus bicirrhosus? Gronov. Syst. ed. Gray p. 158, (Loricaria plecostomus L.).

Ein kleines, ohne die Schwanzflosse nur $52 \mathrm{Mm}$. langes Exemplar aus dem Rio Cadea möchte ich zu dieser Species ziehen. Doch unterscheidet es sich von den mir zur Vergleichung vorliegenden Exemplaren des P. bicirrhosus nicht unbedeutend. Kehle und Bauch sind ganz nackt, die Dornen an allen Schildern der Körperseiten 
sind ziemlich lang, spitz, etwas nach hinten gekrümmt und stehen auf jedem Schilde in nur wenigen, deutlich von einander gesonderten Reihen, während ich bei $P$. bicirrhosus die Unterseite nur dicht hinter dem Umschlag der Unterlippe und in der Gegend um den Ursprung jeder Bauchflosse nackt, sonst aber fein granulirt sehe. Auch sind hier die Seitenschilder viel dichter mit Dornen besetzt, deren Reihen eng aneinander stehen und wenigstens doppelt so zahlreich wie bei meinem Exemplare sind. Da dieses aber sehr viel kleiner als die verglichenen Exemplare der genannten Art und also möglicherweise noch sehr jung ist, so mögen die angeführten Unterschiede vielleicht die Jugend-Charaktere sein.

38. Chaetostomus cirrhosus (Hypostomus cirrhosus Val. in d'Orb. Voy. Amér. Mérid. Poiss. pl. 7. Fig. 3).

Findet sich nicht selten in steinigen Gebirgsbächen, wo er sich nach Art der Plecostomen in dem Schlamm zwischen den Steinen verbirgt.

39. Chaetostomus spinosus? (Hypostomus spinosus, Casteln. Anim. Amér. Sud. Poiss. p. 45. pl. 22. Fig. 3).

Ein kleines, obne Schwanzflosse nur $18 \mathrm{Mm}$. langes Fischchen, welches ich bei Porto Alegre fing, stellt offenbar den Jugendzustand eines Panzerwelses vor. Zwar ist das Interoperculum durchaus ohne die Stacheln der Chaetostomen, doch glaube ich das Thier zu Chaetostomus stellen zu müssen, da wahrscheinlich diese Stacheln in der frühesten Jugend immer fehlen werden. Unter den Arten jener Gattung gleicht es am meisten dem C. spinosus Cast., ohne völlig übereinzustimmen. Jedes Schild an den Seiten trägt nämlich einen verhältnissmässig langen, spitzen und nach hinten gebogenen Dorn, so dass diese im Ganzen fünf Längsreihen bilden. Die unterste Reihe, welche aus den längsten Dornen besteht, gehört wahrscheinlich den Schildern an der Unter. seite des Schwanzes an und scheint auf der Kante zu stehen, in welcher jedes derselben von der Unterfläche 
auf die Seiten des Schwanzes umbiegt. Diese Reihe ist auch die kürzeste, da sie nur, von der Anal- bis zur Caudalflosse reicht. Der erste Strahl aller Flossen, der obere und untere der Caudalflosse, sind ebenfalls mit ähnlichen Dornen besetzt. Im Gesicht entspringt zwischen den Nasengruben ein breiter, stumpfer Kiel, der nach der Spitze des Gesichts herabgeht und auch mit diesen Dornen besetzt ist. Die Farbe (in Spiritus) ist hellbraun mit dunkelbraunen undeutlichen Querbändern. Die ganze Vorderhälfte ist auf der Oberseite dunkel, auf der Hinterhälfte kann man mit einiger Schwierigkeit noch drei Querbänder unterscheiden. Auf der Schwanzflosse sind deren zwei, eins an der Basis und eins am hinteren Rande. Bei C. spinosus sollen sich nur vier Dornenreihen an den Körperseiten finden, auch ist er durchaus anders gezeichnet, allein wir sind mit den Jugendzuständen der Chaetostomen noch zu wenig bekannt, um nach so kleinen Exemplaren, wie das meinige ist, mit Bestimmtheit über die Species entscheiden zu dürfen.

40. Loricaria anus Val. (d'Orb. Voy. Amér. Mérid. Poiss. pl. 6. Fig. 1).

Unter vier Exemplaren ist das grösste (ohne Schwanzflosse) $385 \mathrm{Mm}$. lang. Im Unterkiefer befindet sich jederseits eine Reibe kleiner Zähnchen. Im Oberkiefer fühlt man bloss eine harte Stelle, da wo die Zähne vorhanden waren, bei den kleinsten Exemplare sieht man noch mehrere rudimentäre Zahnspitzen durch das Zahnfleisch hervorragen.

Die Brasilianer nennen diesen Fisch, wahrscheinlich seiner Gestalt wegen, wie alle Loricarien Viòla.

Loricaria lima Kner. (dies. Arch. 1. e. p. 366).

Loricaria strigilata (ebends. p. 368).

Loricaria cadeae (ebends. p. 369).

Loricaria sp.? juv. (ebends. p. 371).

41. Heptapterus mustelinus (Günther, Cat. Fish. V. p. 271. Pimelodus mustelinus Val. in d'Orb. Voy. Amér. Mérid. Poiss. pl. 2. Fig. 1). 
Zwei Exemplare aus einem Bache auf der deutschen Colonie Sta. Cruz in Rio Grande do Sul sind die einzigen dieser Art, die mir vorgekommen sind. Der Fisch muss also ziemlich seiten sein und wird auch nicht durch einen besonderen Namen von Pimelodus sapo unterschieden.

42. Macrodon trahira Müll. Trosch. (Erythrinus trahira Spix.)

Vertritt in Südbrasilien unsern Hecht. Wie dieser vermeidet er das offene Wasser und hält sich lieber in den stillen und seichten, mit Wasserpflanzen erfüllten Buchten auf, wo er am liebsten unter breiten Blättern verborgen auf Beute lauert. Die Brasilianer nennen ihn Trahira.

Macrodon auritus Val. (Cuv. Val. Hist. nat. Poiss. XX. p.519), scheint auf junge Exemplare gegründet zu sein. Wenigstens stimmen mehrere kleine Exemplare, bis zu einer Länge (ohne Schwanzflosse) von $29 \mathrm{Mm}$. herab ziemlich gut mit der Beschreibung dieser Art bei Val. 1. c. Nur sind die Flecken der Seite kaum von einander zu trennen und bilden vielmehr ein schmales Längsband ziemlich in der Mittellinie der Seiten.

\section{Curimatus voga n. sp.}

D. $10-11$. A. $8-9$. L. lat. $36-37$. V. 9.

Länge des Kopfes (ohne den Hautsaum des Kiemendeckels) $4^{1} / 5$ mal und die Höhe des Rumpfes $3 \mathrm{mal}$ in der Körperlänge (ohne Schwanzflosse) enthalten. Die Entfernung der Augen von einander beträgt mehr als das Doppelte ihres senkrechten Durchmessers. Der Anfang der Bauchflossen fällt unter den vierten Strahl der Rükkenflosse. Sie bleiben angedrückt um die Hälfte ihrer Länge vom After entfernt. Auch der Abstand der angedrückten Brustflosse von den Bauchtlossen ist gleich der Hälfte ihrer Länge. Der Anfang der Fettflosse fällt über die Basis des dritten Strahles der Analis. Zwischen den Schuppen der Seitenlinie und den medianen des Rükkens am Anfang der Rückenflosse befinden sich sechs 
Schuppenreihen, ebenso viele unter ihnen bis zur Basis der Bauchflossen (excl.). Das Auge hat ein vorderes und ein hinteres Lied. Alle Flossen unbeschuppt, einfarbig. Die Farbe des Thieres silberglänzend, an Rücken etwas dunkler. An dem kleineren Exemplare ein undeutlicher dunkler Fleck an der Basis der Schwanzflosse. Bei vier jungen Exemplaren, deren grösstes (ohne Schwanzflosse) $29 \mathrm{Mm}$. lang ist, befindet sich ein sehr deutlicher schwarzer Fleck an der Basis der Schwanzflosse, der höher als lang ist und fast die ganze Höhe des Schwanzendes einnimmt. Die Länge des grösseren Exemplares (ohne Schwanzflosse) $190 \mathrm{Mm}$. Aus dem Rio dos Sinos bei S. Leopoldo. Der einheimische Name ist vòga.

Unter allen Fischen, die in Porto Alegre von den Brasilianern mit besondern Namen belegt werden, ist nur ein einziger gewesen, den ich niemals erhalten konnte. Er wurde Crumatá genannt und als dem Voga nahe verwandt bezeichnet. Ohne Zweifel handelt es sich hier um eine zweite Art Curimatus, die möglicherweise auch bisher unbekannt gewesen ist. Der Fisch hält sich, wie auch die vorhergehende Art, mehr in den Zuflüssen des Guahyba, die vom Urwalde herab kommen, auf und wird nur zu gewissen Zeiten gefangen.

44. Leporinus obtusidens Valenc. (d'Orb. Voy. Amér. Mérid. Poiss. pl. 8. Fig. 2).

Ein unter dèm Namen Piába (spr. Piáve) bei Porto Alegre sehr häufiger und sehr geschätzter Fisch, von im Allgemeinen gelblicher Farbe mit drei schwarzen Flecken an der Seite, scheint mir die oben genannte Species zu sein. Leider ist das einzige ganze Exemplar, welches ich aufbewahrt habe, so schlecht erhalten, dass sich eine genaue Bestimmung desselben nicht mehr ausfübren läst. Man sieht nur, dass der erste Fleck über dem Ursprung der Ventralflossen, der zweite über dem After und der dritte an der Basis der Schwanzflosse liegt.

Der Fisch vertritt in der Lebensweise unsern Karpfen in Süd-Amerika und erreicht wie dieser eine bedeutende Grösse, so dass alle Exemplare, die mir zu Gesicht ka- 
men, mit Ausnahme des oben erwähnten, zu gross waren für die mir zur Verfügung stehenden Gefässe. Man fängt diesen Fisch mit Grundangeln, an denen die getrockneten Eier des Arius Commersonii als Köder befestigt sind.

45. Tetragonopterus rutilus? Jenyns (Zool. Voy. of the Beagle P. IV. Fish. London 1842. p. 125. Pl. XXIII. Fig. 2).

D. 11. A. 29. L. lat. 38 .

Das grösste unter zahlreichen Exemplaren ist (ohne Schwanzflosse) $132 \mathrm{Mm}$. lang und $48 \mathrm{Mm}$. hoch. Die Länge des Kopfes beträgt $30 \mathrm{Mm}$; der verticale Durchmesser des Auges, so weit dieses von Aussen sichtbar ist, ist grösser als der horizontale, da der feine und durchsichtige Hautsaum, welcher den Rand der Orbita bildet, an dem Vorderrande derselben breiter ist. Der senkrechte Durchmesser des Auges ist gleich dem Abstande der Augen von einander und der Entfernung des Auges vom hinteren Rande des Kiemendeckels. Das Profil ist gerade, die Stirn von einem Auge zum anderen convex. Zwischen dem Anfange der Rückenflosse und dem der Bauchflossen befinden sich 13-14 Schuppenreiben, deren acht von oben her die Seitenlinie besitzt. Der Anfang der Rückenflosse steht genau senkrecht über dem hinteren Ende der Basis der Bauchflossen. Diese gehen mit ihren Spitzen über den After hinweg, erreichen aber nicht die Analflosse. Diese bei manchen Individuen, und zwar in der vorderen Hälfte, durch kleine Widerhaken raub anzufühlen, bei anderen Individuen nicht. Die Brustflossen erreichen mit ihrer äussersten Spitze die Basis der Bauchflossen. Ihr erster Strahl hat gewöhnlich eine graue Längslinie. Die Entfernung der Fettflosse von der Basis der Rückenflosse ist gleich der Basis der Analflosse. Die Tiefe des Ausschnittes an der Schwanzflosse ist gleich der halben Länge derselben." Die Oberkiefer sind unge zähnt, sie erreichen (bei geschlossenem Munde) die Ver ticallinie des vorderen Randes der Orbita. Im Zwischenkiefer stehen zwei Reihen Zähne, die vorderen sind klein, jederseits $4-5$, und bestehen aus einer Hauptspitze 
welche zu jeder Seite eine kleine Nebenspitze hat. In der hintern Reihe befinden sich jederseits 5-6 Zähne, die viel breiter als die vorderen sind und ebenfalls eine Hauptspitze mit drei Nebenspitzen zu jeder Seite hạben. Die beiden innersten Zähne sind unsymmetrisch, indem die Hauptspitze an ihrer Innenseite nur eine Nebenspitze besitzt. Die Zähne des Unterkiefers, fünf in jeder Hälfte, sind höher und schmäler als die hinteren des Zwischenkiefers. Sie haben zu jeder Seite der Hauptspitze 3, zuweilen auch nur zwei Nebenspitzen.

Die Farbe (in Spiritus) ist im Allgemeinen hellsilberfarben, der Rücken bräunlich (im Leben grünlich), die Flossen sind weiss, die senkrechten zwischen den Strahlen mit kleinen schwarzen Pünktchen, die schon mit blossem Auge zu unterscheiden sind. An der Basis der Schwanzflosse bilden diese Pünktchen eine Anhäufung, durch die ein etwas dunkler Fleck entsteht, der aber nur wenig bemerkbar ist und sich allseitig allmählich verläuft. Nacn vorn $z u$ kann man ihn allenfalls bis zur Verticalen des Hinterendes der Basis der Analflosse verfolgen, nach hinten zu erstreckt er sich auch auf die Membranen zwischen den drei innersten Strahlen der Schwanzflosse, bis zu ibrem Ende,' und färbt sie dadurch rauchgrau. An der Schulter und zwar auf der 3ten und 4ten Querschuppenreihe hinter dem oberen Ende des Kiemendeckels befindet sich ebenfalls eine Anhäufung jener Punkte, die sich wohl auf 4-5 Schuppen erstreckt, aber aus so zerstreuten Punkten besteht, dass sie erst bei der Besichtigung mit der Lupe deutlich wird. Bei der Besichtigung mit blossem Auge bemerkt man hier nur eine Spur eines Schattens, den man leicht übersieht. Bei kleineren Individuen, z. B. $75 \mathrm{Mm}$. lang und kürzer, ist der Schulterfleck viel deutlicher und erscheint als ein schmaler etwas verwischter rauchgrauer Streifen von oben nach unten gerichtet. Auch der Fleck an der Basis der Schwanzflosse ist deutlich schwärzlich, und über beide, sowie über die ganze Seite des Körpers von dem obern Ende des Kiemendeckels bis zur Caudalis geht ein besonders heller glänzender Streifen und zwar auf der 1 ten und 2 ten 
Längsreihe der Schuppen, von denen der Seitenlinie aus gezählt. In der Tiefe, besonders auf der Schwanzhälfte des Körpers, schimmert dieser Streifen dunkel, da hier das Zellgewebe unter der Haut in einem Streifen von dem oberen Ende des Kiemendeckels bis zur Schwanzflosse dunkel pigmentirt ist. Diese dunkle Zeichnung gehört also nicht der Haut an, sondern schimmert bloss durch diese hindurch, namentlich an solchen Exemplaren, deren Haut erweicht und mit Spiritus durchtränkt ist.

Die Dimensionen dieses Fisches, den ich in sehr zahlreichen Exemplaren und sehr verschiedenen Alterszuständen gesammelt habe, variiren nicht unwesentlich. So ist ein anderes Exemplar bei einer Höhe von $48 \mathrm{Mm}$. deren nur 124 lang. Auch ist bei manchen Individuen der Vorderrücken so stark entwickelt, dass er durch eine Einsenkung in das Profil des Scheitels übergeht. Wenn man sich erinnert, was Herr v. Sie bold in seiner klassischen Arbeit ${ }^{1}$ ) über Carassius vulgaris sagt, so wird man Bedenken tragen, dergleichen Abweichungen in den Körperverhältnissén einen systematischen Werth beizulegen.

Als monströs ist wohl ein Exemplar anzusehen, dessen Bauchflossen zwar in der Form normal entwickelt, aber so klein sind, dass sie dęn After nicht erreichen, während von der Analflosse nur die vordere Hälfte vorhanden ist und hinter ihr die Unterseite durch eine starke Einbuchtung in den freien Theil des Schwanzes übergeht.

Unter allen von mir gesammelten Fischen haben mir die Arten der Gattung Tetragonopterus bei ihrer Bestimmung die grösste Mühe gemacht und doch die geringste Befriedigung gewährt. Die Charaktere dieser Fische sind so wenig in die Auge fallend, und meist den Dimensionen des Körpers entlehnt, oder wiederholen sich bei so vielen Arten, wie der dunkle Fleck an der Schulter und der Basis der Schwanzllosse, dass die Unsicherheit in ihren Bestimmungen einen hohen Grad erreicht hat. Ich habe diese Art anfangs für T. fasciatus Cuv. gehalten, obgleich ihre Dimensionen andere sind, allein Valen-

1) Die Süsswasserfische von Mitteleuropa. Leipzig 1863, p. 102. 
ciennes ${ }^{1}$ ) schreibt ihr eine Grösse von einem Fuss zu, welche die Exemplare aus dem Guahyba bei Porto Alegre niemals erreichen. Nach Günther (Catal. Fish. V. p. 323) soll der Schulterfleck rund sein, während ich ihn bei meinen so zahlreichen Exemplaren sehr verschiedener Grösse stets so gefunden habe, wie er oben beschrieben wurde. Auch wird von Günther l. c. der T. fasciatus aus Mexiko angeführt, während ihn $\mathrm{Cuvier}$ aus Buenos Ayres beschreibt. Ein so ausgedehnter Verbreitungsbezirk für eine so kleine und, wie es scheinen möchte, von localen Verhältnisse so abhängige Art hat aber etwas Un. wahrscheinliches. Freilich entspricht die Figur der mir vorliegenden Individuen auch nicht ganz dẻr Abbildung des T. rutilus bei Jenyns l. c., auch haben sie grössere Augen, als diese zeigt, allein theils kann hieran auch eine Ungenauigkeit in der Abbildung, theils individuelles oder locales Variiren Schuld sein. Was Castelna u ${ }^{2}$ ) als $T$. fasciatus Cuv. abgebildet hat, lässt sich aus der ganz ungenügenden Beschreibung 1. c. p. 66, nicht ermitteln, nur glaube ich mit Bestimmtheit annehmen zu können, dass die Abbildung nicht zu T. rutilus Jen. gezogen werden kann, aber auch von ' $\mathrm{T}$. fasciatus Cuv. unterscheiden sich seine Individuen durch die viel geringere Grösse.

46. Tetragonopterus microstoma? Günther (Catal. Fish. Vol. V. London 1864. p. 323).

D. 11. A. 30 . L. lat. $34-35$.

Das grösste unter zahlreichen Exemplaren ist (ohne Schwanzflosse) $110 \mathrm{Mm}$. lang und $51 \mathrm{Mm}$. hoch. Die Länge des Kopfes beträgt $25 \mathrm{Mm}$. Der Hautsaum der Orbita ist weniger entwickelt als bei der vorhergehenden Art, daher ist auch der senkrechte Durchmesser des Auges nur undeutend grösser als der horizontale, er beträgt $8 \mathrm{Mm}$. Der Abstand der beiden Augen von

1) Cuv. et Val. Hist. nat. Poiss. Tom. XXII. p. 150.

2) Anim. nouv. etc. de l'Amer. du Sud. Tom. II. Paris 1855. Pl. 32. fig. 2. 
einander ist $11 \mathrm{Mm}$. gross. Zwischen dem Ursprung der Rückenflosse und den Bauchflossen befinden sich 14 Schuppenreihen, auf deren achten die Seitenlinie verläuft. Der Ursprung der Rückenflosse fällt hinter die Basis der Bauchflosse und zwar in die Mitte dieser, wenn sie an den Bauch gelegt sind. Sie gehen mit ihren äussersten Spitzen über den After hinweg, erreichen aber nicht die Analflosse. Diese ist so lang wie die Entfernung der Basis der Rückenflosse von einem Punkte, der um die Breite der Fettflosse hinter dieser und zugleich in der Verticalen des binteren Endes der Basis der Analflosse liegt. Die Brustflossen erreichen mit ibren äussersten Spitzen die Basis der Bauchflossen. Die Analflosse fühlt sich nur bei dem grössten Exemplare und zwar in ihrem Vorderende etwas rauh an, sonst ist sie glatt, auch bei allen kleineren Individuen.

Die Zähne sind im Allgemeinen wie bei der vorhergehenden Species, nur zeigen sie kleine Unterschiede in den Dimensionen, die sich durch Worte nicht gut wiedergeben lassen. Die Farbe (in Spiritus) ist auch wie bei der vorhergehenden Art, nur ist der Fleck an der Basis der Schwanzflosse sehr deutlich, ebenso der Schulterfleck, welcher grauschwarz und scharf begrenzt eine eiförmige Gestalt hat und mit der Längsachse horizontal gestellt ist.

Auch die Bestimmung dieser Art scheint mir sehr unsicher, da $\mathrm{Hr}$. Günther 1. c. ausdrücklich angiebt "very similar to T. fasciatus," während mir die von mir gesammelten Exemplare von denen der vorhergehenden Art, die ohne Zweifel dem T. fasciatus ähnlich ist, sehr verschieden $\mathrm{zu}$ sein scheinen. Das zoologische und das anatomische Museum zu Berlin besitzen in mehrfachen Exemplaren einen Tetragonopterus, der noch von $J_{0} h$. Nü̈ller's eigner Hand als $T$. bimaculatus M. Tr. bezeichnet ist. Die Beschreibung dieser Art war wahrscheinlich für die Hor. Ichth. bestimmt, ist aber niemals publicirt worden. Sie scheint mit meinen Exemplaren ganz übereinzustimmen, doch besitzt natürlich der Name keine Prioritäts-Rechte. $\mathrm{Zu}$ bemerken ist jedoch noch, 
dass die beiden Individuen, welche in der Sammlung des anatomischen Museums unter N. 13434 aufbewahrt werden, durch ihre viel grösseren Augen von denen des zoologischen Museums wesentlich verschieden $\mathrm{zu}$ sein scheinen.

47. Tetragonopterus alburnus n. sp. D. 10. A. 27. L. lat. 37.

Das einzige Exemplar ist (ohne Schwanzflosse) $60 \mathrm{Mm}$. lang und $17 \mathrm{Mm}$. hoch. Die Länge des Kopfes beträgt $12,5 \mathrm{Mm}$. Das Auge sehr gross, ungefähr so hoch wie breit. Der senkrechte Durchmesser desselben 5,5 Mm., der Abstand der Augen von einander $5 \mathrm{Mm}$., der Ober. kiefer zahnlos und lang, reicht mit seinem hinteren Ende bis unter die Mitte des Auges. Zwischen dem Ursprung der Rückenflosse und den Bauchflossen befinden sich 9 Schuppenreihen, auf deren sechster die Seitenlinie verläuft, so dass also diese so tief zu liegen kommt, wie bei keiner anderen Species. Die Brustflossen erreichen mit ihren Spitzen den Ursprung der Bauchflossen, und diese fast den der Analflosse. Der Ursprung der Rückenflosse fällt ungefähr in die Mitte des Raumes zwischen Bauchflossen und Analflosse. Die Basis dieser ist etwas länger als der Raum zwischen dem hinteren Ende der Basis der Rückenflosse und der Spitze der angedrückten Fettflosse. Die Schwanzflosse ist bis zur Mitte eingeschnitten. Anal- und Bauchflossen sind rauh.

Die Farbe wie auch die ganże Gestalt gleicht der des Alburnus lucidus Heck. (Cyp. alburnus L.). Die Seiten und der Bauch sind silberweiss, der Rücken im Leben bläulich grün. Im Spiritus ist der Rücken gelblich, da hier wegen des fehlenden Silberglanzes das durch die Einwirkung des Spiritus gelbliche Muskelfleisch durch die durchsichtigen Schuppen hindurchschimmert. An der Schulter befindet sich ein dunkler Fleck, der sich schon bei genauerer Betrachtung mit dem blossen Auge in dicht gedrängte, dunkle Punkte auflöst und mit der grös seren Achse senkrecht gestellt ist. An der Basis der Schwanzflosse sind die dunkeln Punkte so zerstreut, dass sie keinen Fleck bilden, sondern jene so wie die ganze 
Schwanzflosse etwas grau färben. Von dem Schulterfleck bis zur Basis der Schwanzflosse, also in der Vorderhälfte des Körpers oberhalb der Mittellinie der Seiten und überhaupt auf der Grenze gegen den dunkeln Rücken ist der Silberglanz am stärksten und bildet hier ein schmales, glänzendes Längsband, aus dessen Tiefe der schon oben beschriebene dunkel pigmentirte Streifen des Zellgewebes durch die Haut hindurch leuchtet.

Die Zähne sind im Ganzen wie bei den vorhergehenden Arten, nur sind sie entsprechend den schlanken Verhältnissen des Thieres feiner und spitzer, auch ist die gelbliche Färbung nur sehr schwach und auf die äussersten Spitzen beschränkt. Aus dem Rio Cadea.

48. Tetragonopterus obscurus n. sp.

D. 11. A. 21-22. L. lat. 38 .

Das grösste unter dreizehn Exemplaren hat folgende Dimensionen: Länge (ohne Schwanzflosse) $60 \mathrm{Mm}$. Grösste Höhe $20 \mathrm{Mm}$. Länge des Kopfes 16,5 Mm. Senkrechter Durchmesser des Auges 5,5 Mm. gleich dem Abstande der Augen von einander. Der Ursprung der Rückenflosse fällt sehr wenig hinter die Basis der Bauchflossen. Diese erreichen mit ihren Spitzen nicht den Ursprung der Analflosse und werden nicht erreicht von den Spitzen der Brustflossen. Die Basis der Analflosse ist sehr kurz, ihr hinteres Ende fällt genau unter den Ursprung der Fettflosse. Zwischen dem Ursprung der Rücken- und Bauchflossen sind 11 Schuppenreihen, auf deren 7 ten die Seitenlinie verläuft. Die Entfernung zwischen Rückenflosse und Fettflosse ist nur sehr wenig länger als die Basis der Analflosse. Der Oberkiefer erreicht die Verticale des vorderen Randes der Orbita. Der Farbe nach ist diese Species unter den vorher beschriebenen die dunkelste, da der Silberglanz bei ihr sehr zurücktritt und eigentlich nur an den Seiten des Kopfes und Bauches vorhanden ist. Im Allgemeinen zeigt die Haut zahlreiche dunkle Punkte, die besonders nach der Rückenkante zu dicht gedrängt stehen, und diese (in Spiritus) bräunlich färben. Auch auf den Kiemendeckeln, deren Grund- 
farbe aus Silberglanz besteht, finden sich zahlreiche dunkle Pünktchen, während sie bei den vorhergenannten Arten nur glänzend silberhell sind. Auch alle Flossen zeigen diese Pünktchen in verschiedener Menge, am meisten die verticalen Flossen, am wenigsten Brust- und Bauchflossen. An der Basis der Schwanzflosse befindet sich ein langer, bandartiger Fleck, der sich auch auf die innersten Strahlen der Schwanzflosse erstreckt. Ein deutlicher aber nicht ganz schwarzer Schulterfleck erstreckt sich von oben nach unten, indem er nach unten zu spitz verläuft. Die Flossen zeigen keine Rauhigkeit. Die Zähne zeigen nichts Abweichendes.

Aus dem Rio Cadea oberhalb des grossen Wasserfalles. Nahe verwandt scheint T. brevimanus Günther (Catal. Fish. V. p. 325) zu sein, doch ist bei diesem nach der Beschreibung der Abstand der Augen von einander grösser als der Durchmesser derselben, es fehlt ihm auch der dunkle Schulterfleck, und die Zahl der Schuppenreihen unterhalb der Seitenlinie ist grösser.

49. Tetragonopterus aeneus $\mathrm{n} . \mathrm{sp}$. D. 11. A. 28. L. lat. 38.

Die Dimensionen des einzigen Exemplars sind folgende: Länge (ohne Schwanzflosse) $80 \mathrm{Mm}$. Grösste Höhe $28 \mathrm{Mm}$. Länge des Kopfes $20 \mathrm{Mm}$. Senkrechter (grösster) Durchmesser des Auges $7 \mathrm{Mm}$. gleich dem Abstand der Augen von einander. Der Okerkiefer reicht hinter die Verticale des vorderen Randes der Orbita, bis zu der des vorderen Randes der Pupille. Zwischen dem Ursprung der Rückenflosse und den Bauchflossen befinden sich 13 Schuppenreihen, auf deren achten die Seitenlinie verläuft. Die angedrückten Brustflossen überragen deutlich den Ursprung der Bauchflossen, welche die Analflosse mit ihren Spitzen nicht erreichen. Die Basis dieser beginnt senkrecht unter dem hinteren Ende der Basis der Rückenflosse und endet senkrecht unter dem hinteren Ende der Basis der Fettflosse. Das Thier ist nicht so dunkel wie die vorhergehende Art, aber dunkler als die beiden zuerst angeführten Arten. Der Silberglanz (in 
Spiritus) ist nicht weiss, sondern bläulich oder grünlich, je nachdem Lichtreflex, auf den Kiemendeckeln fast weiss oder schwach gelblich. Die dunklen Punkte sind im All. gemeinen nicht so zahlreich, wie bei der vorhergehenden Art, fehlen aber doch nur auf der Bauchkante und sind auf den Kiemendeckeln selbst zahlreich, wenn auch nicht so dunkel, wie bei der vorhergehenden Art. Auch die Flossen sind alle deutlich gesprenkelt. An der Basis der Schwanzflosse ein dunkler Fleck, der auch den mittelsten Theil der Schwanzflosse färbt und sich als ein breites schwarzes Band bis über die Mitte der Analflosse verfolgen lässt, wo er allmählich erlischt. An der Schulter ein dunkler nicht sehr deutlicher Fleck, der sich nach unten zu verschmälert. Die Zähne zeigen nichts Besonderes. Von Porto Alegre, zusammen mit den beiden zuerst beschriebenen Arten gefangen.

Alle Tetragonopterus-Arten heissen bei dem Brasilianer in Rio Grande do Sul Lambari. Sie vertreten in den dortigen Flüssen unsere kleinen Cyprinaiden und leben stets schaarenweise an allen ihnen Nahrung versprechenden Orten. Ihre Gefrässigkeit ist gross, und es bedarf nicht erst eines Köders an der Angel, um sie zu fangen, denn sie schnappen begierig nach jedem in's Wasser fallenden Körper und versuchen selbst an der Hand zu zupfen, die man in's Wasser hält. An den Füssen der Badenden sind es besonders die Haare, welche ihre Aufmerksamkeit erregen, und die abzureissen sie sich bemühen. - Die Kiemen der bei Porto Alegre gefangenen Lambari waren stets voll von einem durch blaue Oeltropfen und blaue Eier ausgezeichneten Tracheliastes.

Salminus Orbignyanus Val. (dies. Arch. l. c. p. 356). 50. Xiphoramphus hepsetus (Müll. Trosch. Hor. Ichth.I. p. 17 und 32).

(Xiphorhynchus hepsetus Cuv. Val. XXII. p. 343.)

Bei zahlreichen von mir gesammelten Exemplaren dieser Art erreichen die Brustflossen mit ihren Spitzen den Ursprung der Bauchflossen und überragen ihn auch noch mehr oder weniger weit, ohne jedoch ihre Mitte 
zu erreichen. Da nur bei X. pericoptes (Müll. Trosch. l. c. p. 18 und 32, Tab. V. Fig. 1) die Brustflossen den Ursprung der Bauchflossen nicht erreichen, bei X. hepsetus aber bis zu deren Mitte gehen sollen, so dürften wohl beide Species in eine zusammenfallen.

Bei einem (ohne Schwanzflosse) $143 \mathrm{Mm}$. langen Exemplar beträgt die Höhe $36 \mathrm{Mm}$. und die Länge des Kopfes $44 \mathrm{Mm}$. Doch kommen auch Individuen vor von mehr als 1' Länge. Je älter, d. h. je grösser die Thiere sind, um so weiter überragen die vordersten grossen Zähne des Zwischenkiefers die Spitzen des Unterkiefers. Aus dem Guahyba bei Porto Alegre.

51. Xiphoramphus Jenynsii Günther (Cat. Fish. V. p. 864. p. 356).

D. 11. A. 27. L. lat. 63.

Ein einziges Exemplar dieser Art wurde zugleich mit denen der vorhergehenden Art gefangen. Es ist (ohne Schwanzflosse) $102 \mathrm{Mm}$. lang und $30 \mathrm{Mm}$. hoch. Der Oberkiefer ist viel weniger vorstehend, als bei $\mathrm{X}$. hepsetus, so dass die beiden vordersten Zähne des Zwischenkiefers noch die Haut an den Spitzen des Unterkiefers berühren und hier 2 Furchen in dieselbe eingedrückt haben.

Rivulus ocellatus (dies. Arch. 1. c. p. 365).

Poecilia unimaculata Val. (dies. Arch. 1. c. p. 358). Girardinus januarius (dies. Arch. 1. c. p. 358).

Girardinus caudimaculatus (dies. Arch.1. c. p. 362). Gurardinus decemmaculatus Jen. (dies. Arch. 1. c. p. 364).

52. Carapus fasciatus Müll. Trosch. (Gymnotus fasciatus Bloch.).

Bei Porto Alegre im Guahyba fing ich ein nur $56 \mathrm{Mm}$. langes Fischchen, welches sich in Nichts von der genannten Art unterscheidet und also wohl als ein sehr junges Exemplar derselben zu betrachten ist. Bemerkenswerth ist dann die geopraphische Verbreitung der Art, die vorzugsweise aus Cayenne bekannt ist. Auch ist auf- 
fallend, dass man in Südbrasilien für diesen Fisch, der doch eine beträchtliche Grösse erreicht, keinen besonderen Namen hat. Auf dem Markte in Porto Alegre habe ich ihn niemals gesehen.

\section{Synbranchus marmoratus Bloch.}

Von den Brasilianern Mussúm genannt, findet sich sehr hänfig bei Porto Alegre im Guahyba sowohl wie in vielen kleinern Gewässern, nicht selten sogar in Gräben und Brunnen, die ganz isolirt und ziemlich weit ab von jedem grösseren Wasserbecken liegen. Daher ist über ihn die Ansicht verbreitet, er entstehe aus Schlamm.

Schliesst man von der Zahl der hier beschriebenen Fischarten die beiden ersten, Sciaena adusta und Mugil liza als Seefische aus, die nur gelegentlich das Süsswasser besuchen, so bleiben deren noch 51 übrig, die allein dem Süsswasser angehören. Unter diesen befinden sich 4, Callichthys arcifer, Rivulus ocellatus, Poecilia unimaculata, Girardinus januarius, die nur bei Rio de Janeiro gefunden wurden. Eine Art, Geophagus brasiliensis, erhielt ich sowohl in Rio de Janeiro wie in Porto Alegre. Alle Uebrigen rühren aus dem Flussgebiet der Jacuhy her. Im Ganzen beträgt die Zahl der Arten, welche ich glaubte als neu ansehen zu müssen, 23. Unter diesen sind 3 von Rio de Janeiro.

Wie man sieht, gehören die neuen Arten vorzugsweise solchen Gattungen an, die im Verborgenen leben, in kleinen Tümpeln oder in den Bächen des gebirgigen Urwaldes. Die meisten der hierhergehörigen Fische entziehen sich durch ihre Kleinheit leicht der Beobachtung und werden auch von den Eingebornen nicht beachtet. Es wäre gewagt, aus den gefundenen Daten jetzt schon allgemeine Schlüsse über geographische Verbreitung der Fische u. s. w. ziehen zu wollen, denn einmal muss man gestehen, dass in der Bestimmung der Fischspecies noch grosse Unsicherheit herrscht. Sind wir doch erst in neu ster Zeit über Deutschlands Fische durch die Untersuchungen v. Siebolds aufgeklärt worden. Dann aber 
kann man wohl voraussetzen, dass viele der von mir als neu aufgestellten Arten bei genauerem Nachsuchen auch. in anderen Theilen Südamerika's werden aufgefunden werden, wenn dem Forscher mehr Gelegenheit geboten werden wird, in das Innere der unwegsamen Urwälder einzudringen und hier nicht bloss zu reisen, sondern auch Station zu machen.

Die grösseren Fische, welche sich auch vorzugsweise in ausgedehnteren Gewässern aufzuhalten pflegen, sind zum Theil mit denen des La Plata identisch, vorausgesetzt, dass diese sich in der That von ihren Verwandten im übrigen Brasilien so specifisch unterscheiden, wie man das bisher annimmt.

(Fortsetzung folgt.) 


\section{$2 \mathrm{BHL}$ Biodiversity Heritage Library}

1870. "Beiträge zur Kenntniss der Wirbelthiere Südbrasiliens." Archiv für Naturgeschichte 36, 50-91. https://doi.org/10.5962/bhl.part.25780.

View This Item Online: https://www.biodiversitylibrary.org/item/31389

DOI: https://doi.org/10.5962/bhl.part.25780

Permalink: https://www.biodiversitylibrary.org/partpdf/25780

\section{Holding Institution}

MBLWHOI Library

\section{Sponsored by}

MBLWHOI Library

\section{Copyright \& Reuse}

Copyright Status: NOT_IN_COPYRIGHT

This document was created from content at the Biodiversity Heritage Library, the world's largest open access digital library for biodiversity literature and archives. Visit BHL at https://www.biodiversitylibrary.org. 